\title{
Comparison of enzyme linked immunosorbent assay and enzyme linked fluorescence immunoassay for detection of antibodies against Chlamydia trachomatis
}

\author{
K NUMAZAKI, S CHIBA, T MOROBOSHI, T KUDOH, T YAMANAKA, T NAKAO \\ From the Department of Paediatrics, Sapporo Medical College, Sapporo, Japan
}

SUMMARY An enzyme linked fluorescence immunoassay (ELFA) has been evaluated for the detection of antibodies against Chlamydia trachomatis. Reticulate bodies and elementary bodies from $C$ trachomatis $\mathrm{L}_{2} / 434$ strain were used as antigens. An enzyme linked immunosorbent assay (ELISA) has also been evaluated using the same antigens. Results obtained by ELISA and ELFA for human sera with these two antigens were compared with each other and with the results obtained by a micro-immunofluorescence (micro-IF) test. Serum IgG antibodies against $C$ trachomatis $\mathrm{L}_{2}$ reticulate bodies and elementary bodies were found in $32(20.0 \%)$ and $11(6.9 \%)$, respectively, of 160 serum samples from pregnant women by the micro-IF test (titre $\geqslant 1 / 32)$. All of these 32 pregnant women had IgG antibodies to $C$ trachomatis reticulate bodies (titre $\geqslant 1 / 100)$, whereas $20(12 \cdot 5 \%)$ had IgG antibodies to elementary bodies in the ELISA. On the other hand, $25(15.6 \%)$ and $19(11.9 \%)$ of them had $\mathrm{IgG}$ antibodies to $C$ trachomatis $\mathrm{L}_{2}$ reticulate bodies and elementary bodies, respectively, by the ELFA (titre $\geqslant 1 / 500$ ).

Recently, Chlamydia trachomatis has proved to be a major aetiological agent in sexually transmitted disease in adults and an important cause of respiratory tract and ophthalmic infections in children. ${ }^{12}$ The most reliable method of diagnosing $C$ trachomatis infection is isolation of the organism in tissue culture. Recovery rates, however, are affected by the way in which the clinical specimens are obtained, transported, and stored and by the techniques of tissue culture.

Several serological methods have been developed to detect antibodies to $C$ trachomatis. The standard complement fixation test is not sufficiently sensitive or specific for diagnosing $C$ trachomatis infection. ${ }^{3}$ The micro-immunofluorescence (micro-IF) test of Wang and Grayston, ${ }^{4}$ which uses elementary bodies of $C$ trachomatis as test antigens, is a sensitive and specific method. ${ }^{5}$ The standard micro-IF test, however, requires highly skilled techniques and special reagents, and so a simplified micro-IF test using reticulate bodies of $C$ trachomatis as antigen has been developed. ${ }^{67}$

Enzyme linked immunosorbent assay (ELISA), originally described by Engvall and Perlmann ${ }^{8}$ and Van Weeman and Schuurs, ${ }^{9}$ has been used to detect

Accepted for publication 30 August 1984 antibodies to chlamydia. ${ }^{10-12}$ Recently, enzyme linked fluorescence immunoassay (ELFA) using a fluorogenic substrate has been shown to be more sensitive than standard ELISA for detecting antibodies to some infecting agents. ${ }^{13-15}$

In the present study elementary bodies and reticulate bodies were separated and used as test antigens in ELISA and ELFA. The results obtained with these two methods were compared with each other and with the micro-IF test.

\section{Material and methods}

\section{ANTIGENS}

C trachomatis $\mathrm{L}_{2} / 434 / \mathrm{Bu}$ strain was kindly supplied by Dr Julius Schachter, University of California, San Francisco. Elementary body antigen for use in the micro-IF test was prepared from HeLa 229 cells infected with the above strain as described Kuo et al. ${ }^{16}$ Reticulate bodies were harvested from HeLa 229 cells after inoculation of the same strain of $C$ trachomatis by a modification of the method of Yong et al. ${ }^{7}$ After the cells had been disrupted by sonication, reticulate bodies were separated by differential centrifugation $(500 \mathrm{~g}$ for $10 \mathrm{~min}$ and $30000 \mathrm{~g}$ for $30 \mathrm{~min}$ ) and purified through a $30 \%$ Renografin cushion at $22000 \mathrm{~g}$ for $40 \mathrm{~min}$. They were then fixed 
in $6 \%$ formalin in phosphate buffered saline (PBS).

For the ELISA and ELFA, elementary bodies from $C$ trachomatis $\mathrm{L}_{2} / 434 / \mathrm{Bu}$ were harvested from HeLa 229 cells after inoculation and subjected to differential centrifugation as described above. The elementary body pellet was treated with RNase and DNase (Miles Laboratories) at $37^{\circ} \mathrm{C}$ for $60 \mathrm{~min}$ before the final separation on Renografin gradients. The elementary body pellet was washed in PBS and suspended in PBS containing $0.1 \%$ formalin. Reticulate body antigen used in ELISA and ELFA was prepared in the same way as for the micro-IF test. Elementary body and reticulate body protein concentrations were determined by the method of Bradford. ${ }^{17}$

\section{ANTISERA}

Hyperimmune rabbit serum was obtained from a rabbit immunised with $C$ trachomatis $\mathrm{L}_{2}$ strain $^{18}$ and used to determine appropriate protein concentrations.

\section{CLINICAL SPECIMENS}

Serum specimens were obtained from 160 pregnant women admitted to a maternity clinic in Sapporo City, Japan.

\section{MICRO-IF}

The micro-IF test was performed with reticulate bodies and elementary bodies as single antigens according to methods described previously. ${ }^{57}$

\section{ELISA}

The ELISA was performed by the standard method using reticulate body and elementary body antigens. Based on the protein content, reticulate bodies and elementary bodies were diluted to the appropriate concentration in $0.05 \mathrm{M}$ carbonate-bicarbonate buffer, $\mathrm{pH}$ 9.6. One hundred microlitres of antigen suspension was used to coat each well of a 96 well polystyrene microtitre plate (Dynatech Laboratories Inc, Alexandria, Va). The microtitre plate was incubated overnight at $4^{\circ} \mathrm{C}$ for passive absorption. The antigen suspension was aspirated, and each well was washed three times with PBS (pH 7.3) and $0.05 \%$ (vol/vol) Tween 20 (Sigma Chemical Co, St Louis, Mo) (PBST). The wells were then filled with $100 \mu$ l of $1.0 \%$ bovine serum albumin (BSA) in PBS and left at room temperature for at least $4 \mathrm{~h}$ to block remaining sites of the well. The wells were washed once with PBST and $100 \mu \mathrm{l}$ of diluted serum added to each well. The plate was then incubated for $2 \mathrm{~h}$ at $37^{\circ} \mathrm{C}$ and washed three times with PBST. To each well was added $100 \mu \mathrm{l}$ of a 1/2000 dilution in PBST of horseradish peroxidase labelled rabbit antihuman IgG or swine antirabbit
IgG (Dako, Copenhagen, Denmark). After further incubation for $2 \mathrm{~h}$ at $37^{\circ} \mathrm{C}$, the conjugate was removed by aspiration, and each well was again washed three times with PBST. Substrate, consisting of $50 \mathrm{ml}$ of $50 \mathrm{mM}$ citrate buffer, $\mathrm{pH} 5 \cdot 1$, containing $20 \mathrm{mg}$ of orthophenylenediamine (Sigma) and $20 \mu \mathrm{l}$ of $30 \%$ hydrogen peroxide, was then added to a volume of $100 \mu \mathrm{l} /$ well. The enzyme was allowed to act for $20 \mathrm{~min}$ and then stopped with $50 \mu \mathrm{l}$ of $4 \mathrm{~N}$ sulphuric acid. The absorbance at $486 \mathrm{~nm}$ was determined in a spectrophotometer. A control well without antigen was run for each serum tested, as were control wells without serum (both with and without antigen) for each plate tested. Serum antibody titres were determined by a cut off absorbance of known negative controls.

\section{PROCEDURE OF ELFA}

Wells of a polyvinyl microtitration plate (B plate; Dynatech Laboratories Inc) were coated with reticulate body and elementary body antigens as described above. After incubation overnight at $4^{\circ} \mathrm{C}$, the plate was washed once with PBST. The wells were then filled with $100 \mu$ l of $1.0 \%$ BSA in PBS and left at room temperature for $4 \mathrm{~h}$. After this the wells were washed once with PBST and $100 \mu \mathrm{l}$ of diluted serum was added to each well. The plate was then incubated for $2 \mathrm{~h}$ at $37^{\circ} \mathrm{C}$ and washed five times with PBST. To each well was added $100 \mu \mathrm{l}$ of a $1 / 10000$ dilution in PBST of $\beta$-galactosidase labelled goat antihuman IgG (Zymed Laboratories Inc, South San Francisco, California). After further incubation for $2 \mathrm{~h}$ at $37^{\circ} \mathrm{C}$, the conjugate was removed by aspiration and each well was again washed five times with PBST. Substrate containing $\quad 0.0025 \%$ 4-methylumbelliferyl- $\beta$ - $D$-galactopyranoside (Koch-Light Laboratories, Colnbrook Bucks) in 0.01 M sodium phosphate buffer ( $\mathrm{pH} 7.0)$ was added to a volume of $100 \mu \mathrm{l} /$ well. The enzyme was allowed to act for $20 \mathrm{~min}$ and then stopped with $100 \mu$ l of $0.1 \mathrm{M}$ glycin-NaOH buffer. The fluorescence unit (FU) of each well was determined with a Dynatech MicroFluor reader (1 fluorescence unit = $0.5 \times 10^{-12} \mathrm{M}$ methylumbelliferone).

\section{Results}

DETERMINATION OF OPTIMAL CONDITIONS FOR ELISA AND ELFA

Titrations were performed on different concentrations of antigens and on appropriate dilutions of sera that were either negative or positive in the micro-IF test. Coating with antigen at a concentration of 2.5 $\mu \mathrm{g} / \mathrm{ml}$ or greater gave equally good results in the assays, as determined by the ratio of absorbance with positive (hyperimmune serum of rabbit) and 


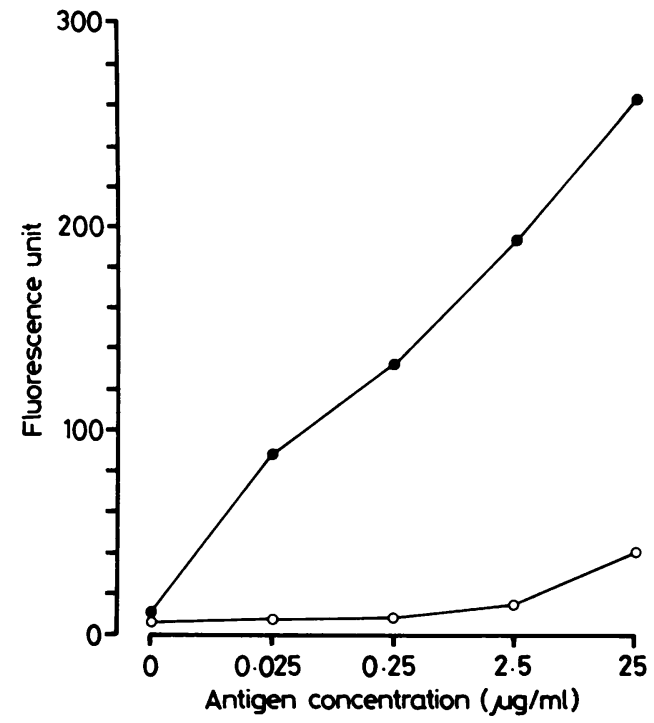

Fig. 1 Effect of the concentration of antigen solution of reticulate bodies in the ELFA. $100 \mu \mathrm{l}$ of various dilutions of $C$ trachomatis $L_{2} 1434$ reticulate bodies was allowed to absorb in wells overnight at room temperature. An ELFA was performed using a 1/500 dilution of known positive (O-O, titre 1/2048) and known negative $\left(O_{-}\right)$) sera with ELISA.

negative (preimmune serum of rabbit) sera. Antigen concentrations of $10 \mu \mathrm{g} / \mathrm{ml}$ for elementary bodies and 2.5 for reticulate bodies were chosen for use in subsequent experiments (Figs. 1 and 2). To establish a cut off absorbance (or fluorescence) which would distinguish positive from negative rẹsults, the net

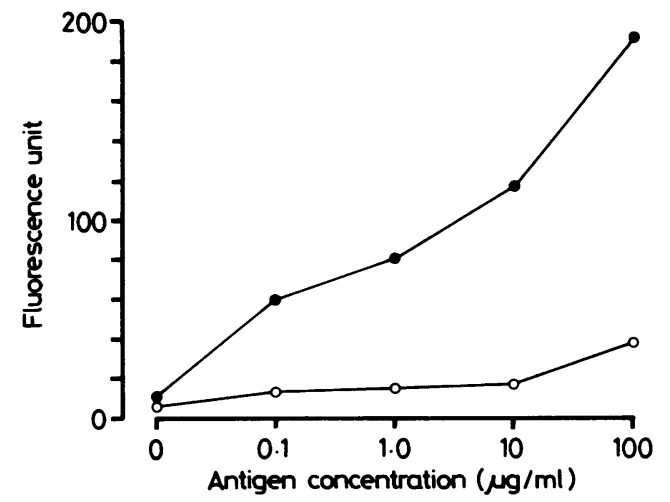

Fig. 2 Effect of the concentration of antigen solution of elementary bodies in the ELFA. $100 \mu$ of various dilutions of $C$ trachomatis $L_{2} / 434$ elementary bodies was allowed to absorb in wells overnight at room temperature. An ELFA was performed using a $1 / 500$ dilution of known positive $\left(O_{-}\right.$, titre 1/1024) and known negative (O-O) sera with ELISA.

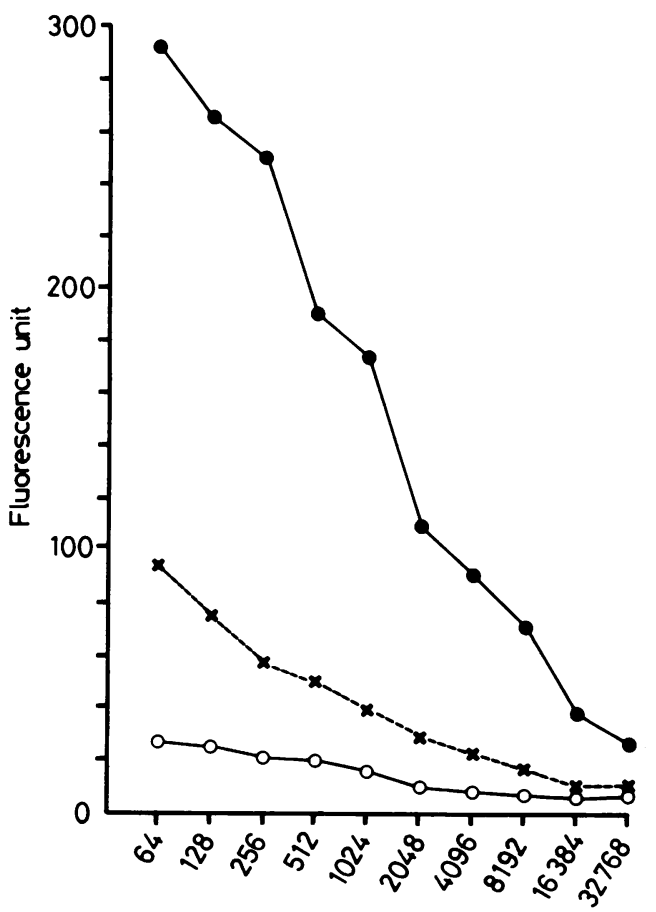

Reciprocal serum dilution

Fig. 3 ELFA titration curve for serum IgG antibody against $C$ trachomatis $L_{2} / 434$ reticulate bodies. Results for positive sera with ELISA titre 1/2048 (๑-@) and 1/256 $(X \ldots X)$, and negative sera $(\mathrm{O}-\mathrm{O})$.

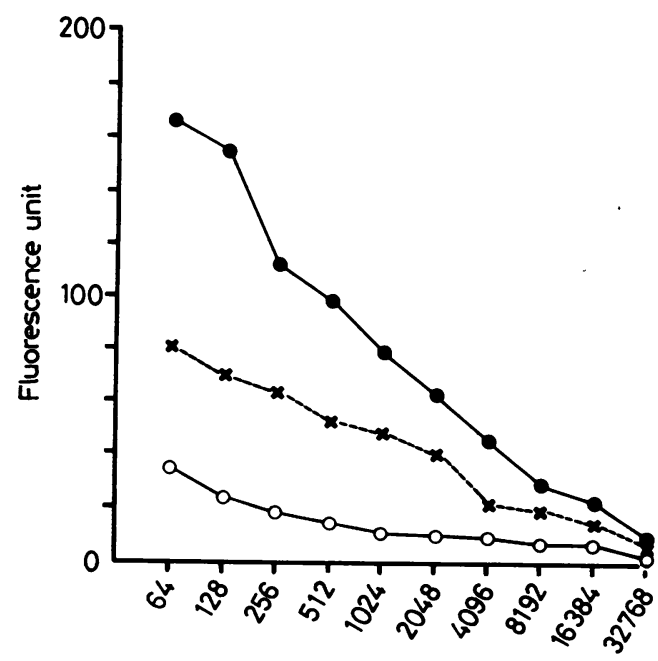

Reciprocal serum dilution

Fig. 4 ELFA titration curve for serum $\operatorname{Ig} G$ antibody against $C$ trachomatis $L_{2} 1434$ elementary bodies. Results for positive sera with ELISA titre 1/1024 (@-Q) and 1/128 $(X \ldots X)$, and negative sera $\left(\mathrm{O}^{-} \mathrm{O}\right)$. 


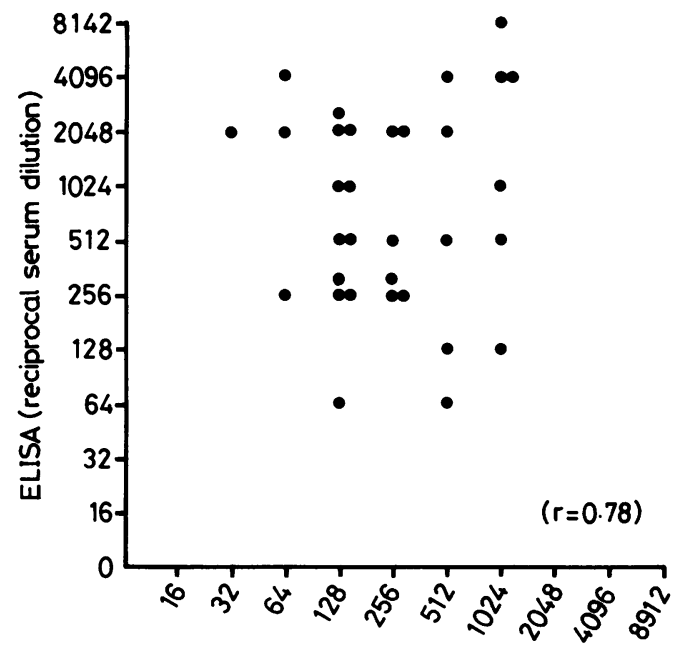

Micro-immunofluorescence (reciprocal serum dilution)

Fig. 5 Scatter diagram of Ig $G$ titres against $C$ trachomatis $L_{2} / 434$ reticulate bodies obtained by ELISA and micro-immunofuorescence. Titres are plotted as the reciprocal of serum dilution.

absorbance (fluorescence) of each serum was determined by subtracting the absorbance (fluorescence) read on the control coated plates from the absorbance (fluorescence) read on $C$ trachomatis $\mathrm{L}_{2}$ coated plates. Positive sera had net absorbance (fluorescence) values more than three times the standard deviation of negative sera. Based on these

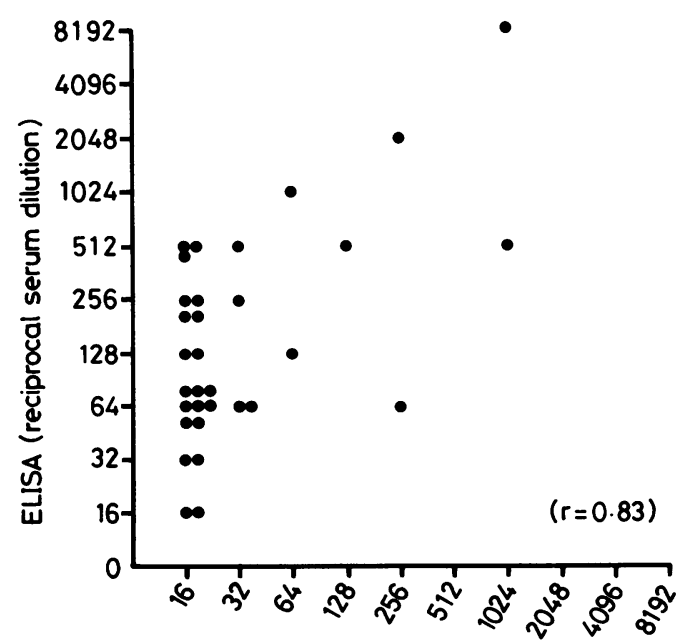

Micro-immunofluorescence (reciprocal serum dilution)

Fig. 6 Scatter diagram of IgG titres against $C$ trachomatis $L / 434$ elementary bodies obtained by ELISA and micro-immunofuorescence. Titres are plotted as the reciprocal of serum dilution.

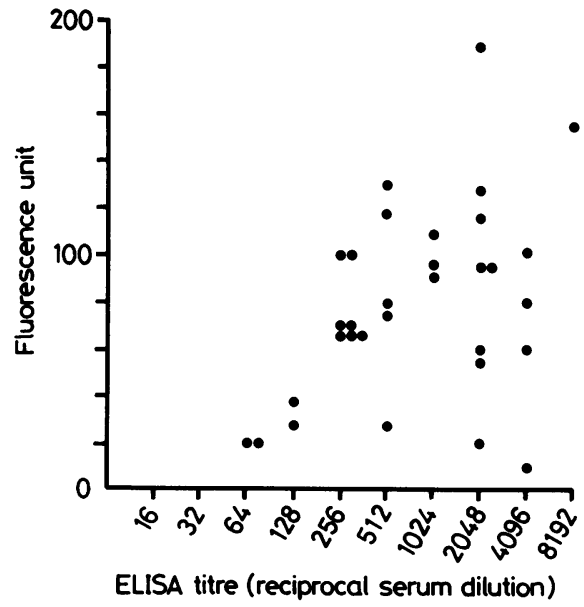

Fig. 7 Scatter diagram of $\mathrm{Ig} G$ titres against $C$ trachomatis $L_{2} / 434$ reticulate bodies obtained by ELISA and ELFA. ELISA titres are plotted as the reciprocal of serum dilution. Fluorescence units of tested sera in ELFA are plotted at the dilution of $1 / 500$.

findings we set a standard cut off value of 0.20 for ELISA and 50 FU for ELFA (Figs. 3 and 4). Subsequent tests showed that this choice of an arbitrary cut off value did not compromise the assay's sensitivity. Two to tenfold enhancement of the micro-IF test endpoint was usually seen by ELISA. Greater enhancement of the ELISA endpoint was obtained by ELFA.

TITRATION OF HUMAN SERA BY ELISA AND ELFA Of 160 pregnant women, $32(20.0 \%)$ had IgG antibodies (titre $\geqslant 1 / 32$ ) to reticulate bodies; 11 $(34.4 \%)$ of these $32 \mathrm{had}$ IgG antibodies to elementary bodies as determined by the micro-IF test. These 32 sera were tested for IgG antibodies by

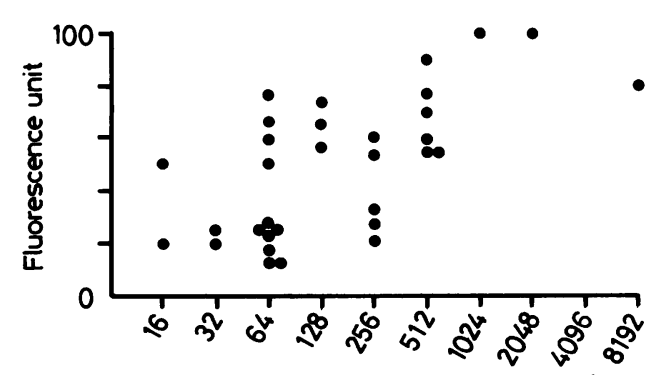

ELISA titre (reciprocal serum dilution)

Fig. 8 Scatter diagram of $\operatorname{Ig} G$ titres against $C$ trachomatis $L_{2} / 434$ elementary bodies obtained by ELISA and ELFA. ELISA titres are plotted as the reciprocal of serum dilution. Fluorescence units of tested sera in ELFA are plotted at the dilution of $1 / 500$. 
ELISA and ELFA. Figs. 5 and 6 compare the results obtained by the ELISA with those obtained by the micro-IF test. The correlation coefficient for IgG results with reticulate bodies was 0.78 and elementary bodies was $\mathbf{0 . 8 3}$, which indicates good agreement between the ELISA results and the currently accepted micro-IF procedure. The FU of the 32 sera determined by ELFA were compared with the endpoints by ELISA (Figs. 7 and 8). The correlation coefficients for IgG results with both reticulate bodies and elementary bodies were less striking. All of 32 pregnant women had antibodies to reticulate bodies in ELISA (titre $\geqslant 1 / 100)$ and $20(12.5 \%$ ) had antibodies to elementary bodies. Antibodies to reticulate bodies and elementary bodies were detected in $25(16.5 \%)$ and $19(11.9 \%)$ of the 32 women respectively by ELFA (titre $\geqslant 1 / 500$ ).

\section{Discussion}

Recently, $C$ trachomatis has become recognised as an important agent of non-gonococcal urethritis in American and European countries, but little has been known about the pathogenic role of $C$ trachomatis in Japanese adults and children. We have used iodine staining of cycloheximide treated McCoy cells and diethylaminoethanol dextran treated HeLa 229 cells for the isolation of $C$ trachomatis. ${ }^{19}$ Because of the considerable prevalence of chlamydial infection in Japan, ${ }^{620}$ there is a great need for sensitive and readily applicable methods to diagnose this infection. Since the isolation by tissue culture is not a readily available diagnostic method, efforts have been made to improve serological methods for the diagnosis of $C$ trachomatis infections.

ELFA has proved to be a simple, reliable, ultrasensitive method for the rapid detection of some infective agents; ${ }^{22}$ it has also been used for the detection of antibodies against some pathogenic agents. ${ }^{1314}$ Yolken and Stopa ${ }^{21}$ have reported that it was roughly 100 times more sensitive than the corresponding ELISA or radioimmunoassay for the detection of human rotavirus in a standard stool suspension. There have been no reports, however, on the use of ELFA to detect antibodies to $C$ trachomatis.

The results of this study support previous findings that the ELISA test is practical and reliable for the detection of IgG antibodies to $C$ trachomatis and show that ELFA also provides a useful method for the detection of these antibodies. Although elementary body antigens from some strains have common antigenicity with some other strains, no elementary body antigen from a single immunotype can detect antibodies against all immunotypes of $C$ trachomatis. ${ }^{5}$ In contrast, reticulate bodies of $C$ trachomatis have group specific antigens shared by all immunotypes of $C$ trachomatis and some strains of $C$ psittaci. ${ }^{7}$ This was also confirmed by our present study, which showed that IgG antibody titres to reticulate bodies were higher than those to elementary bodies both in ELISA and ELFA. The ELISA test was more sensitive than the micro-IF test for detecting IgG antibodies. Titres obtained with the ELFA were higher than those obtained with ELISA. The ELISA as well as the ELFA may detect more cross reacting antibodies than the micro-IF test. $^{10}$ On practical grounds, therefore, reticulate bodies seem to be preferable to elementary bodies as the antigen for use in the ELISA and ELFA for seroepidemiological studies of $C$ trachomatis infections.

The correlation coefficient for IgG results from the ELISA and the micro-IF indicated good agreement between these two methods. There is not enough evidence that the cut off titres for the micro-IF test, ELISA, and ELFA $(32,100,500$ respectively) correlate. The results for the ELISA and ELFA tests showed less satisfactory correlation and further work on this aspect is required.

\section{References}

'Schachter J. Chlamydial infection. $N$ Engl J Med 1978; 298:428-35, 490-5, 540-9.

${ }^{2}$ Schachter J, Grossman M. Chlamydial infections. Ann Rev Med 1981;32:45-61.

${ }^{3}$ Schachter J, Cles L, Ray R, Hines PA. Failure of serology in diagnosing chlamydial infections of female genital tract. J Clin Microbiol 1979; 10:647-9.

4 Wang S-P, Grayston JT. Human serology in Chlamydia trachomatis infection with microimmunofluorescence. J Infect Dis 1974; 130:388-97.

${ }^{5}$ Wang S-P, Grayston JT, Kuo C-C, Alexander RR, Homes KK. Serodiagnosis of Chlamydia trachomatis infection with the microimmunofluorescence test. In: Hobson D, Holmes KK, eds. Non-gonococcal urethritis and related infections. Washington DC: American Society for Microbiology, 1977:237-48.

- Numazaki K, Chiba S, Nakata S, Yamanaka T, Nakao T. Prevalence of antibodies to Chlamydia trachomatis in Japanese persons determined by microimmunofluorescence using reticulate bodies as single antigen. Ped Infect Dis 1984;3:105-9.

' Yong EC, Chinn JS, Caldwell HD, Kuo C-C. Reticulate bodies as single antigen in Chlamydia trachomatis serology with microimmunofluorescence. J Clin Microbiol 1979;10:351-6.

${ }^{8}$ Engvall E, Perlmann P. Enzyme-linked immunosorbent assay (ELISA) quantitative assay of immunoglobulin $G$. Immunochemistry 1971;8:871-4.

${ }^{9}$ Van Weeman BK, Schuurs AH. Immunoassay using antigen enzyme conjugates. FEBS Lett 1971;15:232-6.

${ }^{10}$ Finn MP, Ohlin A, Schachter J. An enzyme linked immunosorbent assay for IgG and IgM antibodies to Chlamydia trachomatis in human sera. J Clin Microbiol 1983;17:848-52.

"Lewis VJ, Thacker WL, Mitchell SH. Enzyme-linked immunosorbent assay for chlamydial antibodies. $J$ Clin Microbiol 1977;6:507-10. 
12 Jones RB, Bruins SC, Wilbert J, Newhall V. Comparison of reticulate and elementary body antigens in detection of antibodies against Chlamydia trachomatis by an enzyme-linked immunosorbent assay. J Clin Microbiol 1983;17:466-71.

${ }^{13}$ Deelder AM, Koper G, DeWater R, et al. Automated measurement of immunogalactosidase reactions with a fluorogenic substrate by the aperture defined microvolume measurement method and its potential application to Schistosoma mansoni immunodiagnosis. J Immunol Methods 1980;36:269-83.

${ }^{14}$ Forghani B, Dennis J, Schmidt NJ. Visual reading of enzyme immunofluorescence assay for human cytomegalovirus antibodies. J Clin Microbiol 1980;12:704-8.

is Kato K, Fukui H, Hamaguchi Y, Ishikawa E. Enzyme-linked immunoassay: conjugation of the Fab' fragment of rabbit IgG with $\beta$-D-galactopyranoside from $E$ coli and its use for immunoassay. J Immunol 1976;116: 1554-60.

${ }^{16}$ Kuo C-C, Wang S-P, Grayston JT. Growth of trachoma organisms in HeLa 229 cell culture. In: Hobson D, Holmes KK, eds. Non-gonococcal urethritis and related infections. Washington DC: American Society for Microbiology, 1977:328-36.

${ }^{17}$ Bradford MM. A rapid and sensitive method for the quantitation of microgram quantities of protein utilizing the principle of protein-dye binding. Anal Biochem 1976;72:248-54.

${ }^{18}$ Caldwell HD, Kuo C-C, Kenny GE. Antigenic analysis of Chlamydiae by two-dimensional immunoelectrophoresis. I. antigenic heterogenecity between $C$ trachomatis and $C$ psittaci. J Immunol 1975; 115:963-8.

19 Numazaki K, Chiba S, Yamanaka T, Umetsu M, Nakao T. Isolation of Chlamydia trachomatis from Japanese infants with pneumonia. Acta Paediatr Jpn 1983;25:249-53.

${ }^{20}$ Numazaki K, Chiba S, Yamanaka T, Umetsu M, Nakao T. Pneumonia due to Chlamydia trachomatis in Japanese infants. Tohoku J Exp Med 1984;143:413-20.

${ }^{21}$ Yolken RH, Stopa PJ. Enzyme-linked fluorescence assay: ultrasensitive solid phase assay for detection of human rotavirus. $J$ Clin Microbiol 1979; 10:317-21.

${ }^{22}$ Yolken RH, Leister FJ. Comparison of fluorescent and colorigenic substrates for enzyme immunoassays.J Clin Microbiol 1982; 15:757-60.

Requests for reprints to: Dr Kei Numazaki, Department of Pediatrics, Sapporo Medical College, S. 1 W. 16 Chuoku, Sapporo, 060 Japan. 